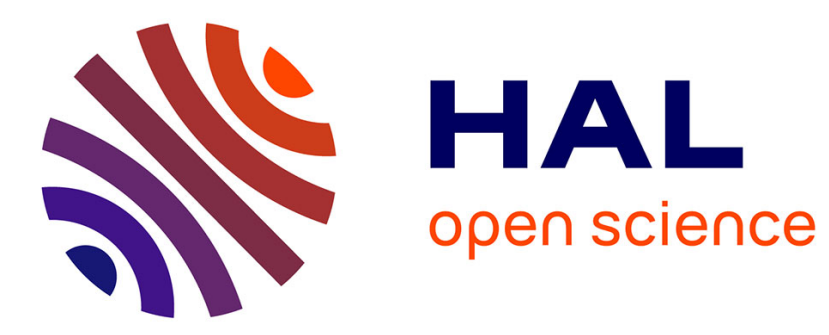

\title{
PROXIMAL PREDICTORS OF CHANGE IN QUALITY OF LIFE AT OLDER AGES
}

Elizabeth A Webb, David Blane, Anne Mcmunn, Gopalakrishnan Netuveli

\section{To cite this version:}

Elizabeth A Webb, David Blane, Anne Mcmunn, Gopalakrishnan Netuveli. PROXIMAL PREDICTORS OF CHANGE IN QUALITY OF LIFE AT OLDER AGES. Journal of Epidemiology and Community Health, 2010, 65 (6), pp.542. 10.1136/jech.2009.101758 . hal-00591157

\section{HAL Id: hal-00591157 https://hal.science/hal-00591157}

Submitted on 7 May 2011

HAL is a multi-disciplinary open access archive for the deposit and dissemination of scientific research documents, whether they are published or not. The documents may come from teaching and research institutions in France or abroad, or from public or private research centers.
L'archive ouverte pluridisciplinaire HAL, est destinée au dépôt et à la diffusion de documents scientifiques de niveau recherche, publiés ou non, émanant des établissements d'enseignement et de recherche français ou étrangers, des laboratoires publics ou privés. 
PROXIMAL PREDICTORS OF CHANGE IN QUALITY OF LIFE AT OLDER AGES INOLDERAGE

3

4

5

6

7

8

10

11

12

13

14

15

16

15

\section{Elizabeth Webb ${ }^{1,2}$, David Blane ${ }^{1,2}$, Anne McMunn ${ }^{1,3}$, Gopalakrishnan Netuveli ${ }^{1,2}$}

1. International Centre for Lifecourse Studies in Society and Health, UK

2. Department of Primary Care and Social Medicine, Imperial College London, London, UK

3. Department of Epidemiology and Public Health, University College London, London, UK

\section{Correspondence:}

Elizabeth Webb, Department of Primary Care and Social Medicine, Imperial College London,

Reynolds Building, Charing Cross Campus, St Dunstan's Road, London W6 8RP

Email: elizabeth.a.webb@imperial.ac.uk

Telephone: 02075940772

Fax: 02075940854

Word count: 2985

Key words: Quality of life measurement, old age 


\section{ABSTRACT}

\section{Objective}

3 To investigate whether changes in health, social and economic circumstances predict change

4 changes in quality of life at older ages.

5 Design

6 Secondary analysis, using multiple regression analyses, of waves 1 and 3 of the English Longitudinal

7 Study of Ageing.

8 Setting

9 England, 2002-2006

\section{Participants}

11 Nationally representative sample of non-institutionalised adults aged over 50 living in England with

12 non-missing data for the variables of interest $(\mathrm{N}=4848)$.

\section{Main outcome measure}

14 Quality of life (QoL) in 2006, with reference to QoL in 2002, both measured using CASP-19 score.

\section{Results}

16 Mean QoL decreased over the four years, with becoming depressed ( $\beta-0.12)$ and developing

17 difficulties with activities of daily living $(\beta-0.08)$ contributing to this decrease. Improvements in

18 family relationships $(\beta 0.10)$, the neighbourhood $(\beta 0.08)$ and perceived financial position ( $\beta 0.07)$

19 each counteracted the decline in QoL. Initial QoL strongly predicted QoL at follow-up ( $\beta$ 0.46).

20 Regression models explained 59\% of variation in QoL, and there were small differences between age

21 and gender groups.

22 Conclusions

23 Maintenance of good QoL in older aged people is enabled by the avoidance of depression,

24 maintenance of physical function, good neighbourhood standards, family relationships and financial 25 circumstances. 


\section{INTRODUCTION}

2 In an era of ageing populations, successful ageing through the maintenance of health and quality of

3 life (QoL) is of primary economic and social importance. Age has a substantial influence on QoL and

4 related measures although the age at which QoL peaks is disputed: two US studies, the first a

5 longitudinal study of nearly 2000 male veterans $^{1}$ and the second the United States General Social

6 Survey $^{2}$ found, respectively, that life satisfaction peaked at 65 years and happiness peaked at 50

7 years. Cross-sectional work using the English Longitudinal Study of Ageing (ELSA) has shown amongst

8 a population of over-50s that average QoL score increased to 68 years and declined thereafter. ${ }^{3}$

9 There is also a body of evidence (e.g. ${ }^{4 ; 5}$ ) which suggests that the curvilinear relationship between

10 age and wellbeing is $\mathrm{U}$-shaped, with a minimum during the late $40 \mathrm{~s}$. However, age does not determine QoL in older ages ${ }^{3 ; 6}$ and, particularly in this time of increasing duration of good health following labour market exit, increasing age need not be greeted with the assumption of declining QoL. Current marital status, ${ }^{3 ; 7}$ social contact and relationships, ${ }^{3 ; 6}$ socioeconomic circumstances ${ }^{3 ; 8}$ and health, ${ }^{3 ; 6 ; 9}$ all influence QoL at older ages, and early life also has an influence which acts through current circumstances, for example property ownership, or life course influences on health. ${ }^{10}$

It has been suggested that individual's QoL is relatively stable over time, even in older age; ${ }^{11}$ that although major events affect it, QoL quickly begins to return to the earlier level, for instance in the case of onset of disability. ${ }^{12}$ Perceived control, a dimension of QoL, has been shown to have weekly variation amongst older people, but that intra-individual magnitude of this fluctuation is stable over time. ${ }^{13}$ What has not previously been investigated is the manner in which common changes in circumstances influence the way in which QoL changes over time in middle and older age. The aim of this longitudinal study is, therefore, to investigate whether change ehanges in QoL over time in older age people over the age of 50 are explained by changes in: i) economic circumstances; ii) social contact and relationships and iii) health. We hypothesise that negative changes in each of these dimensions of life will be associated with decreases in QoL over time, and conversely that improvements in circumstances will be linked to increased QoL. 
2 Data

3 We have used data from the first and third waves of the English Longitudinal Study of Ageing (ELSA),

4 which were collected in 2002 and 2006, respectively. ELSA is a cohort study of a nationally representative sample of non-institutionalised adults who were aged 50 years or older and living in England in 2002. Wave one had a response rate of $67 \%$ and wave three achieved, from those who remained eligible and who responded at wave one, a response rate of $71 \% .{ }^{14}$ Between waves one and three there was $9.4 \%$ mortality amongst the total ELSA sample. ${ }^{15}$ At wave three, 7535 of the original 11234 core members of ELSA remained in the study. Analyses here are based on core ELSA members with no item missingness for the variables of interest, which, in the complete model, results in a sample size of 4848 individuals.

\section{Outcome}

The outcome variable we have used here to indicate change in QoL is CASP-19 score at wave 3 of ELSA, with reference to CASP-19 score at wave 1. QoL measures two waves apart were used although CASP-19 was collected at all waves of ELSA, as the time elapsed between each consecutive wave was too short for sufficient events and changes to have occurred in participant's lives.

CASP-19 is a measure of QoL in older age designed to reflect the features of contemporary society which influence early old age whilst being independent of factors, including financial circumstances and health, which may influence it.

CASP-19 contains 19 Likert-scaled items, which each access one of four domains: Control; Autonomy; Self-realisation and Pleasure. Each item is numerically coded, such that the most positive responses are attributed a score of 3 and the most negative, a score of 0 . The possible range of CASP-19 scores is 0 to 57 , with higher scores indicating a better QoL.

The theoretical background, development and technical properties of CASP-19 are described fully elsewhere. ${ }^{16 ; 17}$ The reliability and validity of CASP-19 as a measure of QoL have also been explored in detail elsewhere ${ }^{17-19}$ each of the four CASP domains is internally consistent with Cronbach's Alpha scores of 0.6 to 0.8 and CASP correlates with the Life Satisfaction Index - well-being scale ${ }^{20}(r=0.63)$.

EASP 19 contains 19 likert-scaleditems, which each access one of four domains: Control; Autenomy; Self realisation and Pleasure. Each item is numerically coded, such that the most positive responses are attributed a score of 3 and the most negative, a score of 0 . The possible range of CASP-19 scores is 0 to 57 , with higher scores indicating a better QoL.

\section{Explanatory variables}

All multivariate models included age, age squared (to account for the non-linearity of the Qelationship and gender and CASP-19 score at baseline (ELSA wave 1). Age squared was included as a covariate as the relationship between QoL and age is non-linear; with increasing age beyond the age of 50 years, QoL has been shown to change in a quadratic manner. ${ }^{3}$

Economic circumstances, social contact and relationships and health indicators were all considered both in terms of baseline levels and change over the follow-up period. The majority of these indicators have been previously shown to predict CASP-19 scores cross-sectionally. ${ }^{3}$ 
1 Indicators of economic circumstances were: i) change in wealth over the follow-up period; ii) wealth

2 at baseline; iii) change in income; iv) income at baseline; v) change in perceived financial position,

3 categorised as up, down or stable and vi) perceived financial position at baseline, dichotomised into

4 those who reported that they managed well or quite well, and those who gave more negative

5 responses.

6 Health indicators included binary variables indicating the presence of long-standing illness (LSI),

7 limiting long-standing illness (LLSI) and depression. This latter variable was derived from the eight

8 item Centre for Epidemiologic Studies Depression (CES-D) scale, from which a score of 3 or more

9 indicated depression. Changes in these binary indicators of health over the follow-up period were

10 defined as improving, static or worsening, with the static group being treated as the baseline.

11 Physical functioning was measured using thirteen activities of daily living (ADL): each activity with

12 which an individual had difficulties was attributed one point and the change in physical functioning

13 defined as the difference between this score at baseline and the end of follow-up.

14 Indicators of social contact and relationships were: whether relationships with i) family and ii)

15 friends were based on understanding, support and confidence; the frequency of contact with iii)

16 family and iv) friends and v) the number of persons with whom participants felt they had close

17 relationships. The five variables were derived from multiple items in the survey, which had multiple

18 ordinal responses. Summary scores were created by summing item responses after ensuring a

19 uniform direction of response with more positive responses being attributed higher scores. Changes

20 in each of these variables were defined as the difference in the score between the waves. Further

21 indicators were changes in marital status, including getting married, separating or divorcing, or being

22 widowed during the follow-up period and marital status at wave one, categorised into married,

23 single, separated or divorced, or widowed.

24 A summary score indicating the characteristics of the neighbourhood in which participants lived was

25 based on nine items, including the presence of vandalism, a sense of belonging, trust and support.

26 These items were each scored with values from 0 to 6 and they were summed to give a single score

27 ranging from 0 to 54 , a higher score indicating a better neighbourhood with more positive

28 characteristics.

29 Analysis

30 Baseline characteristics of those included in analyses and excluded due to missing data were

31 compared using chi-squared and student's t-tests. Preliminary analyses calculated the mean CASP-19

32 score at baseline and mean changes in CASP-19 scores over the follow-up period, by age, gender,

33 income, baseline CASP-19 score and LSI. Student's t-tests tested differences between groups. Those

34 whose CASP-19 score increased were compared in terms of all covariates of interest using chi-

35 squared and student's t-tests to those whose score decreased.

36 Conditional change multiple linear regression models were fitted. The dependent variable was

37 CASP-19 score at wave 3 and CASP-19 score at wave one was included as an independent variable,

38 to account for the lack of independence between QoL scores. Models included: i) age, age squared

39 and gender; ii) as previous, plus health, economic and social measures at baseline; iii) as previous,

40 plus change in health, economic and social measures over the follow-up period. To further

41 investigate the effects of age and gender the analysis was repeated separately for three baseline age

42 groups $(50-64,65-74,75+)$ and for men and women. 
1 All analyses were conducted using Stata SE version 10. 


\section{RESULTS}

2 Those excluded from the analyses, either due to point missingness or absence from wave 3 of ELSA,

3 were older, had lower incomes and baseline QoL, and were more likely to have a LLSI (table 1).

4 Table 1. Comparison of ELSA participants included and excluded from analyses, with $p$-values

5 indicating results of chi-squared and student's t-tests of the differences between groups.

\begin{tabular}{lccccc|} 
& Included & \multicolumn{2}{c|}{ Excluded due to point } & \multicolumn{3}{c|}{ Excluded as not present in } \\
& $\begin{array}{l}\text { (N=4848) } \\
\text { Mean [SD] or \% }\end{array}$ & \multicolumn{2}{c|}{ missingness (N=2456) } & \multicolumn{2}{c|}{ Wave 3 (N=3973) } \\
& Mean [SD] or \% & $\mathrm{p}$ & Mean [SD] or \% & $\mathrm{p}$ \\
\hline Age (years) & $63.1[9.1]$ & $65.3[10.1]$ & $<0.001$ & $67.6[11.4]$ & $<0.001$ \\
Female gender & 54.8 & 56.6 & 0.133 & 52.7 & 0.051 \\
Income (f10 000S) & $1.56[2.03]$ & $1.11[2.14]$ & $<0.001$ & $0.58[1.29]$ & $<0.001$ \\
CASP & $43.4[8.2]$ & $42.3[8.4]$ & $<0.001$ & $41.1[9.4]$ & $<0.001$ \\
LLSI & 29.9 & 35.3 & $<0.001$ & 41.2 & $<0.001$ \\
\hline
\end{tabular}

$6 \quad \operatorname{tin} f 10000 \mathrm{~s}$

7

8 CASP-19 score (range 0-57, baseline median 45) decreased by a mean of 2.2 CASP units over the

9 follow-up period (table 2). This decrease in QoL did not differ according to gender, but was greater in

10 older age groups; those aged 75 and over experienced a decrease 2.5 times greater than those

11 younger than 65 (-3.8 CASP units compared to -1.5$)(p<0.001)$. QoL decreased most amongst: people

12 of intermediate income at wave $1(p=0.003)$; people with median and above initial CASP-19 scores

13 ( $p<0.001)$; people without a LLSI at wave $1(p<0.001)$. 
1 Table 2. Description of the variables used in the study. Unadjusted baseline CASP-19 scores and 2 change in CASP-19 score (mean [SD 95\% 1 ]), according to sociodemographic variables in the 5434 3 participants with complete information on CASP-19 at waves 1 and 3 of ELSA.

\begin{tabular}{|c|c|c|c|}
\hline Variable & Number & Wave 1 CASP score & Change in CASP score \\
\hline All & 4848 & $43.4[8.243 .2,43.6]$ & $-2.2[6.6-2.4,-2.0]$ \\
\hline \multicolumn{4}{|l|}{ Age (years) } \\
\hline $50-64$ & 2835 & $43.5[8.443 .2,43.8]$ & $-1.5[6.6-1.8,-1.3]$ \\
\hline $65-74$ & 1388 & $43.9[7.843 .5,44.3]$ & $-2.9[6.3-3.2,-2.6]$ \\
\hline $75+$ & 625 & $41.9[7.941 .3,42.6]$ & $-3.8[6.9-4.3,-3.3]$ \\
\hline \multicolumn{4}{|l|}{ Gender } \\
\hline Female & 2656 & $43.4[8.043 .1,43.7]$ & $-2.2[6.5-2.5,-1.9]$ \\
\hline Male & 2192 & $43.4[8.4,43.0,43.7]$ & $-2.2[6.7-2.5,-2.0]$ \\
\hline \multicolumn{4}{|l|}{ Wave 1 income tertiles } \\
\hline Lowest & 817 & $41.0[9.340 .3,41.7]$ & $-2.1[7.2-2.6,-1.7]$ \\
\hline Intermediate & 1576 & $42.6[8.142 .1,43.0]$ & $-2.6[6.7-2.9,-2.2]$ \\
\hline Highest & 2455 & $44.7[7.244 .4,45.0]$ & $-2.0[6.2-2.2,-1.7]$ \\
\hline \multicolumn{4}{|l|}{ Wave 1 CASP score } \\
\hline$\leq 44$ & 2304 & $36.6[6.536 .3,36.9]$ & $-0.37[7.1-0.66,-0.08]$ \\
\hline$\geq 45$ & 2544 & $49.6[3.149 .4,49.7]$ & $-3.87[5.6-4.09,-3.66]$ \\
\hline \multicolumn{4}{|c|}{ Wave 1 Long-standing illness } \\
\hline No & 2264 & $45.9[7.045 .6,46.1]$ & $-2.43[6.4-2.69,-2.17]$ \\
\hline Non-limiting & 1135 & $45.0[6.844 .6,45.4]$ & $-2.44[6.1-2.79,-2.08]$ \\
\hline Limiting & 1449 & $38.3[8.737 .9,38.8]$ & $-1.68[7.3-2.05,-1.30]$ \\
\hline
\end{tabular}

4

5 Those whose QoL improved over the follow-up period were younger than those whose QoL

6 decreased, but there were not differences in gender (data not shown). They did not differ in terms

7 of their social contact and relationships or the quality of their neighbourhoods, but in many regards

8 they were at a disadvantage at baseline: initial QoL was lower and, although they had the same

9 objective financial situation, they had a worse perceived financial situation and health at baseline.

10 Over the follow-up period, however, those whose QoL improved experienced more positive

11 changes: a smaller decrease in income and perceived financial situation, health, social contact and

12 relationships and neighbourhoods which were more likely to have improved.

13 In the first multivariate regression model, $49 \%$ of the variation in CASP-19 score at the end of follow-

14 up was explained (table 3). Age and age squared were both associated with CASP-19 score at the 15 end of follow-up, and gender did not have an influence. If other covariates could be held constant, 16 CASP-19 score would fall by around $30 \%$ over the follow-up period.

17 Table 3. Conditional change linear regression model, comparing CASP-19 score at wave 3 to wave 1. 18 Included covariates were age, age squared, gender and CASP-19 at baseline.

\begin{tabular}{|lcccc|}
\hline $\mathrm{N}=4848$ & $\mathrm{~B}$ coeff & $95 \% \mathrm{Cl}$ & $\mathrm{p}$ & Standardised B \\
\hline Age (years) & 0.27 & $0.03,0.52$ & 0.029 & 0.29 \\
Age squared & $-2.88 \times 10^{-3}$ & $-4.76 \times 10^{-3},-1.01 \times 10^{-3}$ & 0.003 & -0.40 \\
Female gender & 0.01 & $-0.34,0.35$ & 0.970 & 0.00 \\
Wave 1 CASP score & 0.71 & $0.69,0.73$ & $<0.001$ & 0.68 \\
Constant & 18.50 & $13.91,23.10$ & - & - \\
$\mathrm{r}^{2}$ & 0.49 & - & - & - \\
\hline
\end{tabular}


1 The second multivariate regression included covariates at baseline and explained $51 \%$ of the

2 variance in CASP-19 score at the end of follow-up (table 4). Main influences were age, age squared

3 and CASP-19 score at baseline, with additional positive influences of economics (wealth, income,

4 perceived financial situation) and aspects of social contact and relationships (quality of family

5 relationships, being widowed, rating of the neighbourhood), and negative influences of poor health

6 (depression, LLSI) and contact with family.

7 Table 4. Multivariate linear regression (conditional change model) of CASP-19 score at wave 3

8 compared to wave 1 , with adjustments for baseline covariates.

\begin{tabular}{|c|c|c|c|c|}
\hline & B coeff & $95 \% \mathrm{Cl}$ & $p$ & Standardised B \\
\hline \multicolumn{5}{|l|}{ Demographics } \\
\hline Age (years) & 0.44 & $0.19,0.69$ & 0.001 & 0.46 \\
\hline Age squared & $-4.09 \times 10^{-3}$ & $\begin{array}{l}-5.98 \times 10^{-3} \\
-2.20 \times 10^{-3}\end{array}$ & $<0.001$ & -0.57 \\
\hline Female gender & 0.08 & $-0.28,0.44$ & 0.661 & 0.00 \\
\hline Wave 1 CASP score & 0.58 & $0.55,0.60$ & $<0.001$ & 0.55 \\
\hline \multicolumn{5}{|l|}{ Economic circumstances } \\
\hline Wealth (f10 000s) & 0.01 & $0.00,0.01$ & 0.001 & 0.03 \\
\hline Income (f10 000s) & 0.14 & $0.04,0.24$ & 0.004 & 0.03 \\
\hline Perceived financial position & 0.78 & $0.39,1.17$ & $<0.001$ & 0.04 \\
\hline \multicolumn{5}{|l|}{ Health } \\
\hline ADL & -0.10 & $-0.25,0.04$ & 0.156 & -0.02 \\
\hline Depression & -1.34 & $-1.83,-0.85$ & $<0.001$ & -0.06 \\
\hline LSI & -0.15 & $-0.58,0.28$ & 0.491 & -0.01 \\
\hline LLSI & -1.02 & $-1.53,-0.51$ & $<0.001$ & -0.05 \\
\hline \multicolumn{5}{|l|}{ Social contact and relationships } \\
\hline Contact with friends & 0.05 & $-0.02,0.12$ & 0.148 & 0.02 \\
\hline Contact with family & -0.09 & $-0.13,-0.04$ & $<0.001$ & -0.06 \\
\hline Quality of friendships & 0.04 & $-0.01,0.09$ & 0.160 & 0.02 \\
\hline Quality of family relationships & 0.08 & $0.05,0.11$ & $<0.001$ & 0.08 \\
\hline Number of close relationships & 0.03 & $0.00,0.07$ & 0.054 & 0.02 \\
\hline Marital Single & -0.44 & $-1.29,0.40$ & 0.304 & -0.01 \\
\hline status at Separated / divorced & 0.01 & $-0.56,0.58$ & 0.968 & 0.00 \\
\hline baseline* Widowed & 0.82 & $0.27,1.37$ & 0.003 & 0.03 \\
\hline Neighbourhood & 0.06 & $0.04,0.08$ & $<0.001$ & 0.06 \\
\hline Constant & 22.55 & $17.84,27.27$ & $<0.001$ & - \\
\hline$r^{2}$ & 0.51 & - & - & - \\
\hline
\end{tabular}

$9{ }^{*}$ Compared to married people

10 tin $f 10000$ s

12 The final multivariate regression included the changes in social, health and economic indicators over

13 the follow-up period. 59\% of the variation in CASP-19 scores at the end of follow-up was explained,

14 with age, age squared and CASP-19 score at wave 1 the strongest predictors (table 5).

15 Improving perceived financial situation and increasing income were linked to increased CASP-19

16 scores at the end of follow-up, whilst worsening perceived financial situation was linked to

17 decreased CASP-19. Changes in wealth did not influence changes in CASP-19, and each additional

$18 f 10,000$ income was associated with 0.1 additional CASP units. 
1 Improving health was linked to higher CASP-19 scores at the end of follow-up, although the negative

2 effects of worsening health were more substantial for both LSI and LLSI. Each additional difficulty

3 with an ADL was linked to a decrease of 0.5 CASP units, whilst becoming depressed was associated

4 with a decrease of 3.5 CASP units. After age and CASP-19 score at wave 1, becoming depressed or

5 recovering from depression were the strongest predictors of final CASP-19 score.

6 Improving quality of relationships and neighbourhood, increasing frequency of contact with friends,

7 increasing numbers of close relationships and being widowed during the period of follow-up were all

8 linked to a higher final CASP-19 score. Increasing frequency of contact with family members was

9 linked to a lower CASP-19 score.

10 Table 5. Multivariate linear regression (conditional change model) of CASP-19 score at wave 3

11 compared to wave 1. All effects shown are of the change in covariates over the follow-up period.

12 Baseline covariates are also included in the model but these effects are not shown here.

\begin{tabular}{|c|c|c|c|c|c|}
\hline \multicolumn{2}{|l|}{$N=4848$} & B coeff & $95 \% \mathrm{Cl}$ & $\mathrm{p}$ & Standardised B \\
\hline \multicolumn{6}{|l|}{ Demographics } \\
\hline \multicolumn{2}{|l|}{ Age (years) } & 0.38 & $0.15,0.61$ & 0.001 & 0.40 \\
\hline \multicolumn{2}{|l|}{ Age squared } & $-3.59 \times 10^{-3}$ & $\begin{array}{l}-5.35 \times 10^{-3} \\
-1.83 \times 10^{-3}\end{array}$ & $<0.001$ & -0.50 \\
\hline \multicolumn{2}{|l|}{ Female gender } & 0.19 & $-0.14,0.52$ & 0.264 & 0.01 \\
\hline \multicolumn{2}{|l|}{ Wave 1 CASP score } & 0.48 & $0.45,0.51$ & $<0.001$ & 0.46 \\
\hline \multicolumn{6}{|c|}{ Economic circumstances } \\
\hline \multicolumn{2}{|c|}{ Wealth ( $f 10000 s)$} & 0.00 & $0.00,0.01$ & 0.095 & 0.02 \\
\hline \multicolumn{2}{|l|}{ Income (f10 000s) } & 0.10 & $0.01,0.20$ & 0.031 & 0.02 \\
\hline \multirow[t]{2}{*}{ Perceived financial position } & Improving & 1.74 & $1.17,2.30$ & $<0.001$ & 0.07 \\
\hline & Worsening & -1.45 & $-1.99,-0.91$ & $<0.001$ & -0.05 \\
\hline \multicolumn{6}{|l|}{ Health } \\
\hline \multicolumn{2}{|l|}{ ADL } & -0.54 & $-0.69,-0.40$ & $<0.001$ & -0.08 \\
\hline \multirow[t]{2}{*}{ Depression } & Improving & 3.44 & $2.74,4.15$ & $<0.001$ & 0.12 \\
\hline & Worsening & -3.46 & $-4.02,-2.90$ & $<0.001$ & -0.12 \\
\hline \multirow[t]{2}{*}{ LSI } & Improving & 0.28 & $-0.30,0.87$ & 0.339 & 0.01 \\
\hline & Worsening & -1.00 & $-1.54,-0.45$ & $<0.001$ & -0.04 \\
\hline \multirow[t]{2}{*}{ LLSI } & Improving & 0.81 & $0.08,1.53$ & 0.030 & 0.03 \\
\hline & Worsening & -1.59 & $-2.16,-1.01$ & $<0.001$ & -0.06 \\
\hline \multicolumn{6}{|c|}{ Social contact and relationships } \\
\hline \multicolumn{2}{|c|}{ Contact with friends } & 0.14 & $0.06,0.21$ & $<0.001$ & 0.05 \\
\hline \multicolumn{2}{|l|}{ Contact with family } & -0.08 & $-0.13,-0.04$ & $<0.001$ & -0.05 \\
\hline \multicolumn{2}{|c|}{ Quality of friendships } & 0.10 & $0.05,0.15$ & $<0.001$ & 0.05 \\
\hline \multicolumn{2}{|c|}{ Quality of family relationships } & 0.11 & $0.08,0.15$ & $<0.001$ & 0.11 \\
\hline \multicolumn{2}{|c|}{ Number of close relationships } & 0.03 & $0.01,0.05$ & 0.004 & 0.03 \\
\hline \multirow{3}{*}{$\begin{array}{l}\text { Changes in marital } \\
\text { status }\end{array}$} & Married & 0.72 & $-0.06,1.50$ & 0.069 & 0.02 \\
\hline & Separated / divorced & -0.28 & $-1.44,0.88$ & 0.637 & 0.00 \\
\hline & Widowed & 0.86 & $0.09,1.64$ & 0.029 & 0.02 \\
\hline \multirow[t]{2}{*}{ Neighbourhood } & Improving & 1.86 & $1.38,2.35$ & $<0.001$ & 0.08 \\
\hline & Worsening & -1.41 & $-1.92,-0.90$ & $<0.001$ & -0.05 \\
\hline \multirow{2}{*}{\multicolumn{2}{|c|}{$\begin{array}{l}\text { Constant } \\
r^{2}\end{array}$}} & 22.59 & $18.19,26.98$ & $<0.001$ & - \\
\hline & & 0.59 & - & - & \\
\hline
\end{tabular}

15 When the final model was re-run for three age groups $(50-64,65-74,75+)$ overall effects were

16 similar, with an indication that economic improvements may have a smaller positive effect in the 
1 oldest age group, and when the same model was run separately for men and women there were no 2 apparent gender effects (data not shown). 


\section{DISCUSSION}

Economic, health and social changes are all linked to change changes in individual's QoL over time. The factors which influence change in QoL relate closely to those which have a cross-sectional relationship with $\mathrm{QoL}^{3}$ and, as there is no sole predictor of QoL, there is no single predictor of change in QoL the way in which QoL changes.

Those factors which have the greatest influence upon change in QoL are age and initial QoL. After these, depression, physical functioning, perceived financial position, quality of family relationships and the quality of the neighbourhood are the strongest influences. All these associations operate in the expected direction, such that a worsening of circumstances is linked to a reduction in QoL. This research confirms previous findings from this and other study populations that strong personal relationships, good health and financial security are important in maintaining a good QoL in older age. $^{3 ; 6-9}$

This research is based upon data from a representative sample of the English population aged over 50 years, but the interpretation of the results outlined here may be limited due to the proportion of missing data. Analyses are based on the 4848 individuals with complete data on all the variables of interest, who remain from the 11234 participants in the first round of ELSA. The majority of this missingness is a result of $35 \%$ of participants who were not present at wave three (for full details of the ELSA response rates, see ${ }^{14 ; 15}$ ) and an additional $17 \%$ of original participants who had one or both measures of CASP-19 missing.

Those included in the analyses and excluded due to missing data differ in terms of age, income, prevalence of LLSI and QoL. These differences, however, do not lead to questions regarding the internal validity of the results, and there is no reason to suspect that the relationship between changes in economic, social and health circumstances and change in QoL would differ in the excluded group. Those participants who remain in the study at the end of follow-up are more advantaged at baseline than those who do not (table 1), providing further evidence for the widely recognised effect that retention in cohort studies is higher amongst those who are more advantaged. ${ }^{21-23}$

The positive correlation between QoL at wave one and QoL at wave three (correlation coefficien $t=0.68$ ) provides evidence for continuity in QoL, despite changes in circumstances leading to changes in QoL. In their study of the effect of incident disability on happiness, Oswald and Powdthavee showed that happiness levels began to recover within a few years. ${ }^{12}$ In order to explore the capacity of individuals to fully recover their previous QoL following a negative change in circumstances, a longer term study is required.

Despite the correlation in individuals' QoL scores over time, there is a trend towards worsening QoL over time at all ages in this middle and older aged population. For example, the CASP-19 score for a 60 year old at the end of follow-up (wave 3,2006 ) is a mean of 2.5 CASP units lower than for a participant of the same age at the beginning of the study (wave 1, 2002). CASP-19 scores at wave 2 of ELSA (2004) were very similar to those at wave 1 , so it is unlikely that the depreciation observed at wave 3 indicates a real fall in QoL. A more likely explanation is that the difference is an artefact; in the wave 3 ELSA questionnaire the QoL section was positioned immediately after the General Health Questionnaire (GHQ), which is designed to detect psychiatric illness and may have left participants 
feeling negative, whilst in the first and second waves it was positioned after more neutral questions about education and qualifications, and about social activities. This potential methodological issue does not, however, invalidate the results reported here. When analyses were repeated investigating the change in QoL between waves one and two of ELSA, rather than waves one and three, the results were very similar. This issue does, however, merit further investigation which is unfortunately outside the scope of this paper.

We have shown in this work that those dimensions of social life, including the quality of relationships with family and friends, the number of close relationships and the frequency of contact with friends, which have a positive influence on QoL cross-sectionally ${ }^{3}$ also have a positive influence on change in QoLthe way in which Qol changes over time, and that changes in these factors also have an influence. Good quality relationships contribute positively to an individual's psychological-wellbeing, ${ }^{24-26}$ a psychological concept which is a dimension of, ${ }^{27 ; 28}$ and correlates highly with, ${ }^{17}$ QoL. Strong social networks may also delay functional decline, ${ }^{29}$ encouraging maintenance of good QoL. which is closely linked to how people evaluate their QoL. The apparent negative influence of frequent contact with family members is in contrast to the positive influence of contact with friends possibly indicating that this contact is related to caring for, or being cared for by, relatives. This contact may be linked to a sense of duty in the former case, or poor health in the latter, and a loss of independence in both situations, therefore explaining the negative impact upon QoL. The negative impact on QoL of caring for dependent elderly relatives is well documented. ${ }^{30 ; 31}$

The positive change in QoL relating to being widowed before or during the follow-up period is unlikely to indicate that being widowed is a positive experience. It may be an indication that these individuals had a particularly low initial QoL, due to recently having been widowed or to caring for a partner in poor health, and QoL improved over the follow-up period as bereaved participants began to recover from grief. The lack of apparent further influence of marital status on QoL may be because the necessary level of detail about individual's circumstances is not available here; the influence of marriage or divorce will depend upon the circumstances of the relationship before the event. It has previously been shown that marriage improves happiness ${ }^{32}$ and well-being ${ }^{33}$ but also that the quality of a marriage, rather than marriage itself, is the important influence upon wellbeing. ${ }^{34}$

Individuals with poor and worsening health and poor and worsening financial circumstances have greater decreases in QoL, however we might note that those health and economic measures which have the greatest influence are those which are subjective or psychologically influenced, rather than objective. For example perceived financial circumstances have a greater influence than either income or wealth, and depression greater than LSI or LLSI. These stronger relationships mirror previous findings, ${ }^{35}$ and reinforce QoL as a subjective measure, which tends to correlate with subjective measures of health and social and economic circumstances.

\section{What was previously known}

Cross-sectionally, social, economic and health factors are associated with QoL in older age.

\section{What this study adds}

QoL declines over time in older aged people, and common changes in circumstances affect the rate of this decline. Improved perception of financial circumstances and quality of neighbourhoods can 
decelerate decline in QoL, as can improving relationships with family members. Becoming depressed and developing difficulties with physical functioning both accelerate decline in QoL.

Qot is declining in older aged people, but potential measures to avoid or reduce this decline include improving the financial situation of older people, improving the neighbourhoods in which older people live and a greater recognition of and improved facilities for the treatment of depression in older people.

This research was funded by ESRC Grant number RES-596-28-0001.

Competing Interest: None declared.

The Corresponding Author has the right to grant on behalf of all authors and does grant on behalf of all authors, an exclusive licence (or non exclusive for government employees) on a worldwide basis to the BMJ Publishing Group Ltd to permit this article (if accepted) to be published in JECH and any other BMJPGL products and sublicences such use and exploit all subsidiary rights, as set out in our licence (http://iech.bmi.com/ifora/licence.pdf). 
Reference List

(1) Mroczek DK, Spiro A. Change in life satisfaction during adulthood: findings from the Veterans Affairs Normative Aging study. Journal of Personality and Social Psychology 2005; 88(1):189202.

(2) Easterlin RA. Life cycle happiness and its sources: Intersections of psychology, economics, and demography. Journal of Economic Psychology 2006; 27(4):463-482.

(3) Netuveli G, Wiggins R, Hildon Z, Montgomery S, Blane D. Quality of life at older ages: evidence from the English Longitudinal Study of Ageing (wave 1). J Epidemiol Community Health 2006; 60:357-363.

(4) Blanchflower DG, Oswald AJ. Is well-being U-shaped over the life cycle? Social Science \& Medicine 2008; 66(8):1733-1749.

(5) Uppal S. Impact of the timing, type and severity of disability on the subjective well-being of individuals with disabilities. Social Science \& Medicine 2006; 63(2):525-539.

(6) Farquhar M. Elderly people's definitions of Quality of Life. Social Science \& Medicine 1995; 41(10):1439-1446.

(7) Haring-Hidore M, Stock W, Okun M, Witter R. Marital status and subjective well-being: a research synthesis. Journal of Marriage and the Family 1985; 47(4):947-953.

(8) Georgellis Y, Tsitsianis N, Yin YP. Personal values as mitigating factors in the link between income and life satisfaction: evidence from the European Social Survey. Social Indicators Research 2009; 91(3):329-344.

(9) Netuveli G, Wiggins RD, Hildon Z, Montgomery SM, Blane D. Functional limitation in long standing illness and quality of life: evidence from a national survey. BMJ 2005; 331(7529):1382-1383.

(10) Blane D, Higgs $P$, Hyde M, Wiggins RD. Life course influences on quality of life in early old age. Social Science \& Medicine 2004; 58(11):2171-2179.

(11) Grundy E, Bowling A. Enhancing the quality of extended life years. Identification of the oldest old with a very good and very poor quality of life. Aging and Mental Health 1999; 3:199-212.

(12) Oswald AJ, Powdthavee N. Does happiness adapt? A longitudinal study of disability with implications for economists and judges. Journal of Public Economics 2008; 92(5-6):10611077.

(13) Eizenman D, Nesselroade J, Featherman D, Rowe J. Intraindividual variability in perceived control in a older sample: the MacArthur successful ageing studies. Psychology and Ageing 1997; 12(3):489-502.

(14) Seminar on attrition and non-response in longitudinal studies of ageing. Institute for Fiscal Studies [ 2009 Available from: URL:http://www.ifs.org.uk/elsa/non response sem.php 
(15) Living in the 21st Century: Older people in England. Banks J, Breeze E, Lessof C, Nazroo J, editors. 2008. London, Institute for Fiscal Studies.

(16) Higgs P, Hyde M, Wiggins R, Blane D. Researching Quality of Life in Early Old Age: The Importance of the Sociological Dimension. Social Policy \& Administration 2003; 37(3):239252.

(17) Hyde M, Wiggins RD, Higgs P, Blane DB. A measure of quality of life in early old age: the theory, development and properties of a needs satisfaction model (CASP-19). Aging \& Mental Health 2003; 7(3):186-194.

(18) Wiggins R, Higgs P, Hyde M, Blane D. Quality of life in the third age: key predictors of the CASP-19 measure. Ageing \& Society 2004; 24:693-708.

(19) Wiggins R, Netuveli G, Hyde M, Higgs P, Blane D. The Evaluation of a Self-enumerated Scale of Quality of Life (CASP-19) in the Context of Research on Ageing: A Combination of Exploratory and Confirmatory Approaches. Social Indicators Research 2008; 89(1):61-77.

(20) James O, Davies AD, Ananthakopan S. The life satisfaction index - well-being: its internal reliability and factorial composition. British Journal of Psychiatry 1986; 149:647-650.

(21) Purdie DM, Dunne MP, Boyle FM, Cook MD, Najman JM. Health and demographic characteristics of respondents in an Australian national sexuality survey: comparison with population norms. J Epidemiol Community Health 2002; 56(10):748-753.

(22) Sonne-Holm S, Sorensen TI, Jensen G, Schnohr P. Influence of fatness, intelligence, education and sociodemographic factors on response rate in a health survey. J Epidemiol Community Health 1989; 43(4):369-374.

(23) Goldberg M, Chastang JF, Leclerc A, Zins M, Bonenfant S, Bugel I et al. Socioeconomic, Demographic, Occupational, and Health Factors Associated with Participation in a Long-term Epidemiologic Survey: A Prospective Study of the French GAZEL Cohort and Its Target Population. Am J Epidemiol 2001; 154(4):373-384.

(24) Umberson D, Chen M, House J, Hopkins K, Slaten E. The effect of social relationships on psychological well-being: Are men and women really so different? American Sociological Review 1996; 61(5):837-857.

(25) Bowling A, Browne PD. Social Networks, Health, and Emotional Well-being Among the Oldest Old in London. J Gerontol 1991; 46(1):S20-S32.

(26) Pinquart M, Sorensen S. Influences of socioeconomic status, social network, and competence on subjective well-being in later life: a meta-analysis. Psychology and Ageing 2000; 15(2):187-224.

(27) Sarvimaki A, Stenbock-Hult B. Quality of life in old age described as a sense of well-being, meaning and value. Journal of Advanced Nursing 2000; 32:1025-1033.

(28) Cohen SR, Mount BM, Tomas J, Mount LF. Existential well-being is an important determinant of quality of life: evidence for the McGill quality of life questionnaire. Cancer 1998;

77(3):576-586. 
(29) Unger J, McAvay G, Bruce M, Berkman LF, Seeman T. Variation in the impact of social network characteristics on physical functioning in elderly persons: MacArthur Studies on Successful Ageing. J Gerontol 1999; 54B(5):S245-S251.

(30) Li TC, Lee XD, Lin CC, Amidon RL. Quality of life of primary caregivers of elderly with cerebrovascular disease or diabetes hospitalised for acute care. Quality of Life Research 2004; 13(6):1081-1088.

(31) Jones D, Peters T. Caring for Elderly Dependants: Effects on the Carers' Quality of Life. Age Ageing 1992; 21(6):421-428.

(32) Stack S, Eshleman JR. Marital Status and Happiness: A 17-Nation Study. Journal of Marriage and Family 1998; 60(2):527-536.

(33) Coombs RH. Marital Status and Personal Well-Being: A Literature Review. Family Relations $/ 1 ; 40(1): 97-102$.

(34) Gove WR, Hughes M, Style CB. Does Marriage Have Positive Effects on the Psychological Well-Being of the Individual? Journal of Health and Social Behavior /6; 24(2):122-131.

(35) Bowling A, Windsor J. Towards the Good Life: A Population Survey of Dimensions of Quality of Life. Journal of Happiness Studies 2001; 2(1):55-82. 